\title{
Production of Furanic Compounds and Organic Acids from Brazilian Pequi (Caryocar brasiliensis Camb.) Residues Using Green Chemistry
}

\author{
Elisandra Scapin, ${ }^{\circledR *, a b}$ Magale K. D. Rambo, ${ }^{\circledR a}$ Guenther C. C. Viana, ${ }^{b}$ \\ Mariana S. Borges, ${ }^{\circledR a}$ Michele C. D. Rambo ${ }^{c}$ and Cláudio Carneiro ${ }^{a}$ \\ aPrograma de Pós-Graduação em Ciências do Ambiente, Universidade Federal do Tocantins (UFT), \\ Campus de Palmas, 77001-090 Palmas-TO, Brazil \\ ${ }^{b}$ Curso de Engenharia Ambiental, Laboratório de Química, Bloco II, \\ Universidade Federal do Tocantins (UFT), Campus de Palmas, 77001-090 Palmas-TO, Brazil
}

'Instituto Federal de Educação, Ciência e Tecnologia do Tocantins, Campus de Palmas, 77020-450 Palmas-TO, Brazil

\begin{abstract}
In the current search for renewable energy sources, residual biomass has gained ground in the concept of biorefinery. Furanic compounds such as 5-hydroxymethylfurfural (HMF), furfural (FF) and derivatives such as levulinic acid (LA), obtained from biomass, have emerged as important industrial chemical platforms. In this sense, this work aimed to use pequi bark, typical biomass and abundant in the Brazilian cerrado, in the production of HMF, FF and LA using the ionic liquid 1- $n$-butyl-3-methyl-imidazole bromide ([BMIM][Br]). The analysis of chemical composition of pequi bark showed that it has potential for use in the production of bioproducts, FF, HMF and LA, with yields of 65,3 and $23.7 \%$, respectively. High glucose conversion rates were found $(>90 \%)$. The analysis of variance (ANOVA) was applied to obtain the mathematical model with $\alpha=0.05$, verifying the significance of the second order model established for HMF $(F=0.00167)$ and FF (0.004494). The model fit is satisfactory, obtaining the coefficient of determination $\left(\mathrm{R}^{2}\right)$ for the HMF and for the FF of 0.9599 and 0.08422 , respectively. From the results obtained, it can be concluded that pequi bark has good precursor capacity for use in biorefinery processes.
\end{abstract}

Keywords: pequi, furanic compounds, residual biomass, Brazilian cerrado

\section{Introduction}

The chemical industry's current reliance on nonrenewable raw materials such as petroleum is a challenge for the sustainable economy in the present century. The impacts caused and the possibility of scarcity aroused the search for economically and environmentally viable energy sources. The use of residual biomass in the biorefinery is favored due to the low cost of operation, reuse of waste, high energy efficiency, renewable source, clean and requires no expansion of new arable land. ${ }^{1}$

In the present scenario, furanic series compounds such as 5-hydroxymethylfurfural (HMF) and furfural (FF) as well as organic acids such as levulinic acid (LA) have gained prominence in biomass conversion processes, allowing a most sustainable chemical route in their production processes. ${ }^{2,3}$

*e-mail: scapin@uft.edu.br
HMF is a valuable biomass-derived compound and the interest is due to its polyfunctional characteristic and consequent ability to form various chemical intermediates and products useful in industrial applications ${ }^{3-6} \mathrm{HMF}$ can be obtained from dehydration of fructose and also from fructose glucose isomerization as well as directly from cellulose.? However, there are several concurrent reactions that may reduce the selectivity in $\mathrm{HMF}^{8}$ production which may be affected by the type of raw material, solvent and the catalyst. ${ }^{9}$

$\mathrm{FF}$, on the other hand, is an input produced in biorefineries, which can be transformed into useful fuels and chemicals used in oil refining, plastics production, the pharmaceutical and agrochemical industry. ${ }^{10}$ Similarly, LA has been the subject of studies ${ }^{11,12}$ due to its diverse industrial applications such as solvents, resins, plasticizers, polymers, herbicides, biofuels, among others. LA has been identified as one of the twelve major chemical platforms by the US Department of Energy ${ }^{13}$ and can be obtained from cellulose-rich biomass resources. ${ }^{14}$ 
In regard to the solvents used to obtain these inputs, aqueous systems stand out because they are economically and environmentally viable, but lead to the formation of large amount of humines and polymerization products, which compromises yield and selectivity. ${ }^{15}$ Organic solvents, on the other hand, minimize the formation of humins, but they have a high environmental impact, fossil origin and high cost. ${ }^{16}$ In this context, ionic liquids (ILs) have been widely used as a solvent and/or catalysts in a sustainable way for carbohydrate dehydration in furanic compounds ${ }^{17}$ and organic acids,,$^{18}$ as they increase conversion rates and selectivity, leading to energy savings compared to conventional solvents. ${ }^{17,19-21}$ Even though IL production is expensive, the fact that they can be reused decreases the effective cost of processing. 22,23

In this context, the fruit of the pequi tree (Caryocar brasiliensis Camb.), popularly known as pequi, is an endemic and multiuse fruit of the Brazilian Cerrado biome, available over 2 million $\mathrm{km}^{2}$ across the country, ${ }^{24}$ has many uses, being applied in various areas of the industry. Its fruit is abundant and has great potential for oil extraction to produce fuels and lubricants, ${ }^{25,26}$ while the peel, which represents about $84 \%$ of the weight of the ripe fruit, even though it has several chemical and medicinal substances, is thrown away. ${ }^{27,28} \mathrm{As}$ a result, the residual biomass generated by pequi bark is very large, with no profitable return and there is no final destination for it.

Given the great need for the development of a diversified and sustainable national energy matrix, motivated not only by scarcity, but also by the major impacts generated by the petrochemical industry, the present work seeks the use of pequi bark for the production of furan compounds HMF and FF, and organic acids using IL. The big challenge is to achieve high selectivity, good yields and low production costs.

\section{Experimental}

\section{Samples}

The bark of pequi (Caryocar brasiliense) used in this work was collected in the early months of 2018, in an indigenous village of the Xerente tribe located in the municipality of Tocantínia, Tocantins State, Brazil. Pequi barks were taken to the Laboratório de Química of Universidade Federal do Tocantins, where they were manually separated, oven dried at $60{ }^{\circ} \mathrm{C}$ for $24 \mathrm{~h}$, ground in a Willye knife mill (star FT 50 model, Fortenox), and stored in tightly sealed glass bottles.

\section{Extractives}

This procedure was performed in a Soxhlet extractor with reaction times $(8 \mathrm{~h})$ associated with high ethanol concentrations (95\%) according to Rambo et al. ${ }^{29}$ The extraction cartridges received about $3 \mathrm{~g}$ of each sample of biomass. After that, they were covered with cotton wool and, then, taken to the extractor with $200 \mathrm{~mL}$ of ethanol. After the end of the reflux, the cartridges were placed on Petri dishes on the counter for $48 \mathrm{~h}$ to be dried. After $48 \mathrm{~h}$, the moisture content of the extracted sample was determined again, so that the extractives content were calculated according to the weight loss after the extraction, deducting the moisture.

\section{Acid hydrolysis}

The acid hydrolysis was performed according to methodology developed by the National Renewable Energy Laboratory (NREL), ${ }^{30}$ where the extracted sample $(300 \mathrm{mg})$ was subjected to a two-stage acid hydrolysis process. In the first step, the sample in $72 \%$ sulfuric acid $(3 \mathrm{~mL})$ was transferred to a water bath (Fisatom, 550) maintained at $50{ }^{\circ} \mathrm{C}$ for $1 \mathrm{~h}$ and stirred every $10 \mathrm{~min}$. In the second stage, $84 \mathrm{~mL}$ of water was added to the sample, and the sample was transferred to an autoclave (autoclave vertical, Phoenix) for $1 \mathrm{~h}$ at $120^{\circ} \mathrm{C}$. The pressure tubes were filtered through medium porosity crucibles (10 to $15 \mu \mathrm{m}$ ) using a vacuum compressor pump (LT 65, Limatec, coupled). The liquid fraction of the hydrolyzate was used for the production of bioproducts.

\section{Lignin content}

The acid insoluble lignin (AIL) and acid soluble lignin (ASL) content in the pre-treated biomass were quantified according to the NREL ${ }^{30}$ laboratory analytical procedure. The insoluble acid residue (IAR) retained in the filter crucibles contained insoluble lignin, from which it was washed with distilled water until complete removal of the acid, and then heated to $105 \pm 5^{\circ} \mathrm{C}$. The ASL content was measured by a UV-Vis spectrophotometer $(\mathrm{HACH} /$ Germany, DR5000) with the wavelength of $294 \mathrm{~nm}$ and the $4 \% \mathrm{H}_{2} \mathrm{SO}_{4}$ solution was used as the blank. The total lignin (TL) is the sum of AIL + ASL.

\section{Moisture}

According to the ASTM D3173-8731 method, the moisture was determined after the sample $(1 \mathrm{~g})$ was heated to $105 \pm 5^{\circ} \mathrm{C}$ in an oven (SolidSteel SSD 110L) for $12 \mathrm{~h}$. 


\section{Ash content}

The ash content (AC) was determined according to the ASTM D3174-04 ${ }^{32}$ and consists of analyzing the residue after combustion in muffle furnace at $600{ }^{\circ} \mathrm{C}$ for $4 \mathrm{~h}$.

\section{Cellulose, hemicellulose and lignin analysis}

The acid detergent fiber (ADF) and cold neutral detergent (FDN), according to Trujillo et al., ${ }^{33}$ were used to determine hemicellulose content, while the lignin was determined by NREL methodologies ${ }^{30}$ and cellulose by difference.

Synthesis of the ionic liquid 1-n-butyl-3-methyl-imidazole bromide

The ionic liquid 1-n-butyl-3-methyl-imidazole bromide ([BMIM][Br]) was synthesized by the reaction with bromobutane and 1-methyimidizole in three round neck bottom flasks fitted with a reflux condenser for $48 \mathrm{~h}$ at $70{ }^{\circ} \mathrm{C}$ with stirring according to the methodology of Dharaskar et al..$^{34}$

\section{Experimental planning}

The experimental planning and analysis was performed using the Protimiza Experimental Design program. ${ }^{35}$ Based on previous experiments and the literature, ${ }^{1,9,36}$ the influence of temperature and reaction time was evaluated using a design composite central rotational (DCCR) with factorial design, ${ }^{22}$ including 4 assays in axial conditions and 3 center point repetitions, totaling 11 trials (Table 1). After the screening, a central composite design was developed to determine the response surface and the optimal point for the FF and HMF selectivity.

\section{Production of HMF and FF}

The production of HMF and FF was performed according to DCCR and adaptations to the methodology contained in the literature, ${ }^{1}$ where in a round bottom flask was added $2.5 \mathrm{~mL}$ of the hydrolyzate, $1 \mathrm{~g}$ of IL [BMIM] $[\mathrm{Br}]$ in an oil bath at different reaction times and different temperatures (Table 1), kept under reflux. After completion of the reaction time, the sample was washed with ethyl acetate three times.

\section{Production of LA}

The production of LA was performed according to Bevilaqua et al..$^{37}$ for the best condition. Two grams ( $2 \mathrm{~g}$ ) of pequi bark were added to $20 \mathrm{~mL}$ of $4.5 \% \mathrm{HCl}$ in an oil bath during $70 \mathrm{~min}$ at $160^{\circ} \mathrm{C}$ under reflux. After completion of the reaction time, the sample was filtered under vacuum, washed to neutral $\mathrm{pH}$ and stored for future analysis. In addition to the experimental procedure described above, the conversion of LA was tested using $750 \mathrm{mg}$ of IL [BMIM][Br], followed by the addition of $25 \mathrm{mg}$ of raw biomass and $75 \mathrm{mg}$ of $\mathrm{H}_{2} \mathrm{O}$.

\section{Fourier transform infrared spectroscopy (FTIR) analysis}

The infrared spectrometer (FT-IR CARY 630, Agilent Technologies) with range of 650 to $4000 \mathrm{~cm}^{-1}$, using ATR diamond crystal (attenuated total reflectance), with $0.4 \mathrm{~nm}$ of increment and 32 scans of averaging was used to analyze all the samples ([BMIM][Br], hydrolyzed and the product after IL reaction).

Table 1. DCCR $2^{2}$ planning matrix with 3 repeats at central point for HMF and FF production

\begin{tabular}{|c|c|c|c|c|c|c|c|c|}
\hline \multirow{2}{*}{ Assay } & \multirow{2}{*}{ time / h } & \multirow{2}{*}{ Temperature $/{ }^{\circ} \mathrm{C}$} & \multicolumn{2}{|c|}{$\mathrm{HMF} / \mathrm{ppm}$} & \multirow{2}{*}{ Yield / \% } & \multicolumn{2}{|c|}{$\mathrm{FF} / \mathrm{ppm}$} & \multirow{2}{*}{ Yield / \% } \\
\hline & & & Experimental & Predict & & Experimental & Predict & \\
\hline 1 & 1 & 100 & 51.11 & 67.64 & 0.91 & 1067.41 & 836.87 & 68.58 \\
\hline 2 & 3 & 100 & 99.80 & 120.50 & 1.78 & 1108.74 & 1149.85 & 71.24 \\
\hline 3 & 1 & 140 & 74.53 & 152.98 & 1.33 & 683.03 & 879.71 & 43.89 \\
\hline 4 & 3 & 140 & 7.85 & 90.48 & 0.14 & 339.59 & 807.99 & 21.82 \\
\hline 5 & 0.5 & 120 & 140.57 & 99.28 & 2.51 & 722.67 & 798.07 & 46.43 \\
\hline 6 & 3.5 & 120 & 138.90 & 92.05 & 2.48 & 1265.86 & 979.01 & 81.33 \\
\hline 7 & 2 & 80 & 51.09 & 57.26 & 0.91 & 704.28 & 858.43 & 45.25 \\
\hline 8 & 2 & 160 & 168.33 & 112.58 & 3.01 & 832.49 & 559.41 & 53.49 \\
\hline 9 & 2 & 120 & 164.06 & 144.50 & 2.93 & 1255.46 & 1133.90 & 80.67 \\
\hline 10 & 2 & 120 & 160.41 & 144.50 & 2.86 & 1080.61 & 1255.45 & 69.43 \\
\hline 11 & 2 & 120 & 169.61 & 144.50 & 3.03 & 1211.00 & 1133.90 & 77.81 \\
\hline
\end{tabular}

HMF: 5-hydroxymethylfurfural; FF: furfural. 
High performance liquid chromatography (HPLC) analysis

To determine the carbohydrates, LA, HMF and FF of the hydrolyzate and after the reaction with ionic liquid, the samples were analyzed by HPLC using Shimadzu ${ }^{\circledR}$ chromatograph (LC-10 Avp series, Kyoto, Japan). Standards for LA, furfural and 5-HMF were purchased from Sigma-Aldrich (St. Louis, MO, USA). All samples were previously diluted and filtered in $0.22 \mu \mathrm{m}$ polyvinylidene difluoride (PVDF) syringe.

Phenomenex Rezex ROA-organic acid $\mathrm{H}^{+}$column (8\%) was used to determine sugar content, using $\mathrm{H}_{2} \mathrm{SO}_{4}$ acid $\left(5 \mathrm{mmol} \mathrm{L}^{-1}\right)$ as eluent, with a flow rate of $0.6 \mathrm{~mL} \mathrm{~min}{ }^{-1}$ and refractive index detector model RID-10A (Shimadzu). The injected sample volume was $20 \mu \mathrm{L}$.

The determination of LA present in the hydrolyzate was determined by liquid chromatography equipment (HPLC, Dionex Ultimate 3000), DAD 3000 diode array spectrophotometric detector, WPS-3000TSL injector module, Aminex HPX-87H column and refractive index detector RI-101 (Shodex). The mobile phase used was $\mathrm{H}_{2} \mathrm{SO}_{4}$ acid $\left(5 \mathrm{mmol} \mathrm{L}^{-1}\right)$ with a flow rate of $0.6 \mathrm{~mL} \mathrm{~min}^{-1}$, the sample injection volume was $20 \mu \mathrm{L}$ and the column temperature maintained at $50{ }^{\circ} \mathrm{C}$. The samples were previously diluted and filtered through a $0.22 \mu \mathrm{m}$ porosity PVDF syringe filter. The concentrations of these compounds were calculated from the calibration curve obtained from the standard LA solution (Sigma-Aldrich, St. Louis, MO, USA, $\geq 98 \%$ purity).

LA yields were calculated according to Tiong et al. ${ }^{38}$ from equations 1-2:

$$
\begin{aligned}
& \text { Theoretical yield of LA }(\% \text { by weight })=\frac{\text { cellulose content } \times 0.71}{\text { biomass content }} \\
& \text { LA yield }(\%)=\frac{(\text { AL concentration }(\mathrm{ppm}) \times \text { liquid volume }(2 \mathrm{~mL})) / 116}{\mathrm{mg} \text { of glycose } / 162} \times 100
\end{aligned}
$$

HMF and furfural determination was performed using Phenomenex Luna column $5 \mu \mathrm{m} \mathrm{C18}(2)(250 \times 4.6 \mathrm{~mm})$ and pre-column Phenomenex C18 $(4 \times 3.0 \mathrm{~mm})$ filled with material similar to the main column. The eluent flow was $1 \mathrm{~mL} \mathrm{~min}{ }^{-1}$ at $30{ }^{\circ} \mathrm{C}$, with a total run time of $10 \mathrm{~min}$. Isocratic elution was performed using an acetonitrile/water solution (1:8 with $1 \%$ acetic acid). The detector used was UV (SPD-10Avp) with a wavelength of $276 \mathrm{~nm}$.

The yields of these compounds were calculated using the equations 3 and 4 proposed by Cai et al. ${ }^{39}$

$$
\begin{aligned}
& \text { HMF yield }(\%)=\frac{(\text { HMF concentration }(\mathrm{ppm}) \times \text { liquid volume }(2.5 \mathrm{~mL})) / 126}{\mathrm{mg} \text { of cellulose } / 162} \times 100(3) \\
& \text { FF yield }(\%)=\frac{(\text { FF concentration }(\mathrm{ppm}) \times \text { liquid volume }(2.5 \mathrm{~mL})) / 96}{\mathrm{mg} \text { of hemicellulose } / 132} \times 100
\end{aligned}
$$

\section{Results and Discussion}

\section{Determination of chemical composition of biomass}

The pequi bark analyzed was collected in a typical cerrado region during the rainy season. As pequi is found in many regions of Brazil, the chemical composition of pequi peel (Caryocar brasiliense) may vary according to soil composition, climatic characteristics and different qualities of the fruit. Table 2 shows the chemical composition of pequi bark.

Table 2. Chemical analysis of the raw dry biomass

\begin{tabular}{lc}
\hline Component & Concentration $\pm \mathrm{SD} / \%$ \\
\hline AIL & $20.76 \pm 0.4$ \\
ASL & $5.48 \pm 0.4$ \\
TL & $25.71 \pm 0.75$ \\
Humidity & $7.00 \pm 0.2$ \\
Ashes & $2.82 \pm 0.2$ \\
CF & $25.27 \pm 0.8$ \\
Cellulose & $36.3 \pm 0.08$ \\
Hemicellulose & $5.35 \pm 0.06$ \\
Extractives & $34.47 \pm 0.8$ \\
\hline
\end{tabular}

SD: standard deviation; AIL: acid insoluble lignin; ASL: acid soluble lignin; TL: total lignin; CF: fixed carbon.

The chemical characterization of bioproducts obtained from pequi bark has shown that this biomass can serve as raw material in the biorefinery field due to the high sugar content (cellulose and hemicellulose, about $41.65 \%$ ). High lignin content (about 25\%) indicates good results during pyrolysis processes. The low moisture content (about 7\%) means a higher yield in bioproducts production, increasing the process efficiency. The low ash content (about 2.82\%) is beneficial in pyrolysis processes and avoids side reactions during hydrolysis. The extractives content was high (about $35 \%$ ) because it is a very oily biomass. ${ }^{25}$

Rambo et al. ${ }^{29}$ performed the chemical characterization of pequi stone, obtaining $7.20 \%$ moisture, $2.86 \%$ ash and $26.80 \% \mathrm{CF}$ (fixed carbon), values very similar to those found in this work. da Paz et al. ${ }^{40}$ determined $52.4 \%$ moisture and $0.7 \%$ ash in the fruit of pequi (Caryocar brasiliense Camb.) in natura. Ramos and de Souza ${ }^{41}$ performed the physical and chemical nutritional characterization of pequi fruits (Caryocar coriaceum Wittm.). In different regions of midnorth of Brazil, there is average pulp moisture content of $31.51 \%$ and ash around $3.05 \%$. Some distinct results found between the works can be justified by taking into account the species analyzed, the part of the fruit used and the place where they were collected. 


\section{FTIR spectroscopy}

The structure of [BMIM][Br] was confirmed by FTIR analysis (Figure 1) and literature data. ${ }^{42,43}$ The peaks at the wavelengths of 2957 and $2868 \mathrm{~cm}^{-1}$ correspond to the asymmetric and symmetrical aliphatic stretching $(\mathrm{C}-\mathrm{H})$ of the methyl groups. A broad peak of $3357-3429 \mathrm{~cm}^{-1}$ occurs due to the formation of the bromine quaternary amino salt. The peaks at $1166 \mathrm{~cm}^{-1}$ correspond to the vibrations of the imidazole ring $\mathrm{H}-\mathrm{C}-\mathrm{C}$ and $\mathrm{H}-\mathrm{C}-\mathrm{N}$ bonds. The band with a wavelength of $825 \mathrm{~cm}^{-1}$ occurs due to $\mathrm{C}-\mathrm{N}$ vibration.

Figure 2 a shows the FTIR spectral profile of pequi bark hydrolyzate and Figure $2 b$ shows the FTIR spectral profile after ionic liquid use. When analyzing the transmittance spectrum of Figure $2 \mathrm{a}$, it can be noted that in the region from 3400 to $3200 \mathrm{~cm}^{-1}$ the characteristic oscillations of the absorptions generated from the vibrational elongation of the $-\mathrm{OH}$ bond present in carbohydrates and water can be attributed. Stretch at $1636 \mathrm{~cm}^{-1}$ is attributed to carbonyl $(\mathrm{C}=\mathrm{O})$ present in $\mathrm{HMF}$, whereas stretch observed at $1182 \mathrm{~cm}^{-1}$ refers to the $(\mathrm{C}-\mathrm{O})$ bond present in carbohydrates and also in HMF. And finally, the bands around $1050 \mathrm{~cm}^{-1}$ are characteristic of cellulose and hemicellulose and their derivatives due to the stretching of the $-\mathrm{C}-\mathrm{O}$ and $\mathrm{C}-\mathrm{C}$ bonds. ${ }^{44}$ Analyzing all data, it is clearly observed that the spectrum of Figure 2a represents the basic structure of sugars. When analyzing the transmittance spectrum of Figure $2 \mathrm{~b}$ we can observe the band in $1736 \mathrm{~cm}^{-1}$ attributed to the vibrational stretch $\mathrm{C}=\mathrm{O}$. In $1371,1234,1043$, and $936 \mathrm{~cm}^{-1}$ the bands corresponding to the $\mathrm{C}-\mathrm{O}$ stretches prove the existence of furanic rings.

\section{Production of furanics and LA}

Table 1 shows the HMF and FF yields obtained after the experimental optimization outlined by the DCCR. FF was produced in $65 \%$ yield after $3.5 \mathrm{~h}$ reaction and $120{ }^{\circ} \mathrm{C}$ temperature, while $\mathrm{HMF}$ reached $3 \%$ yield after $2 \mathrm{~h}$ reaction at $100{ }^{\circ} \mathrm{C}$, both using IL [BMIM][Br].

Some studies in the literature ${ }^{1-34,37-45}$ have reported works with HMF and FF yields close to those found in this work using different residual biomass as raw material. Zhang et $a l .{ }^{21}$ reported the production of HMF and FF from maize ear with yields of about $66 \%$ (after $65 \mathrm{~min}$ reaction) and $10 \%$ (after 85 min reaction), respectively, at $175{ }^{\circ} \mathrm{C}$. Yang et al. ${ }^{46}$ from maize straw using microwave and $\mathrm{AlCl}_{3} \cdot 6 \mathrm{H}_{2} \mathrm{O}$ catalyst, synthesized $\mathrm{HMF}$ and $\mathrm{FF}$ with 19 and $55 \%$ yield, respectively. Wang et al. ${ }^{47}$ obtained HMF in about $23 \%$ yield from wheat straw using IL 1-butyl3-methylimidazole chloride ([BMIM][Cl]). Rambo et al. ${ }^{48}$ obtained HMF and FF yielding 1.5 and $20.0 \%$, respectively, using baru biomass residues, ionic liquid, in an oil bath

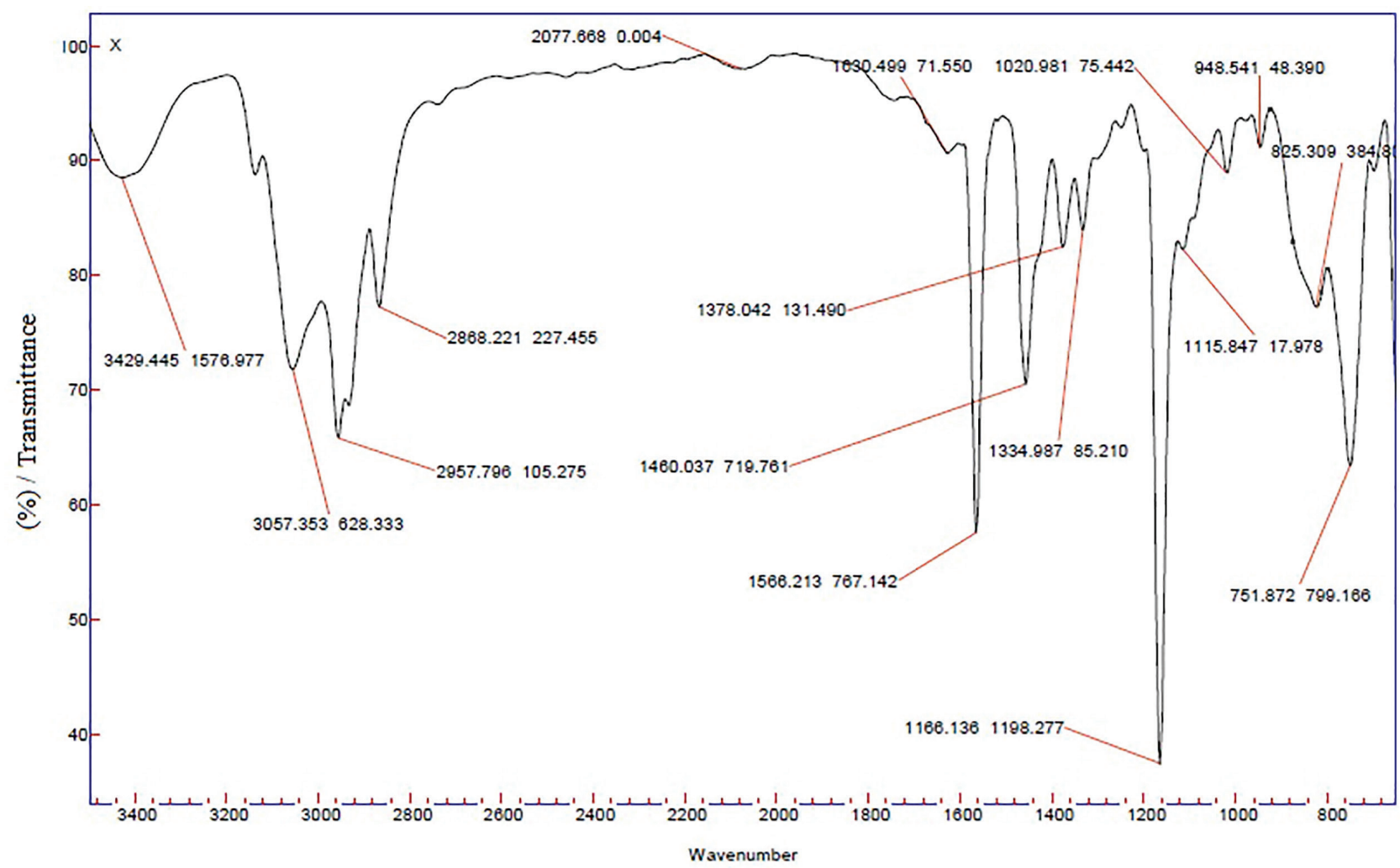

Figure 1. FTIR using ATR of IL [BMIM][Br]. 


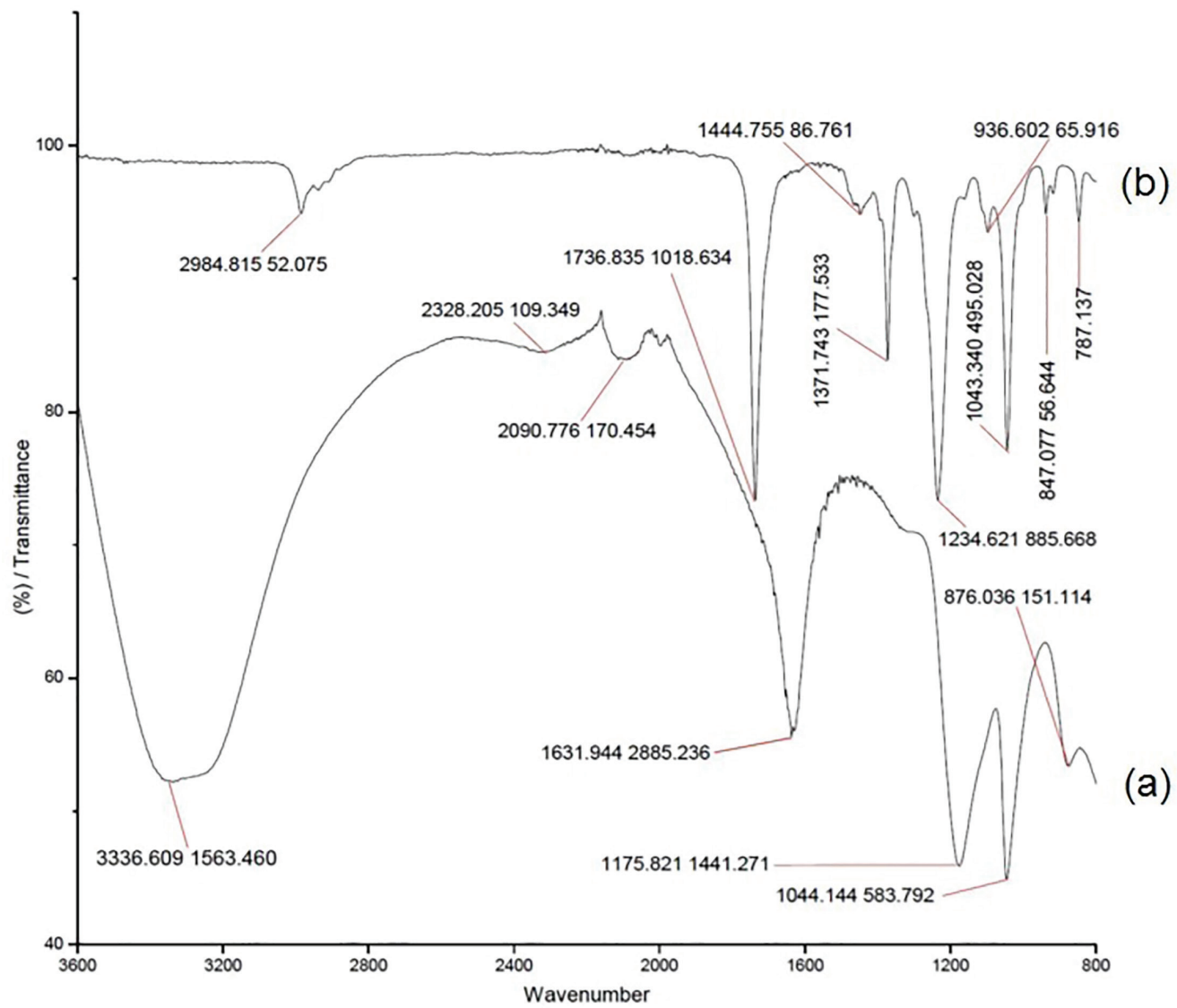

Figure 2. FTIR using ATR analysis of the hydrolyzed peel sample (a) and the product after reaction with the ionic liquid (b).

at $120-140{ }^{\circ} \mathrm{C}$ for reaction times of $1-2 \mathrm{~h}$. In a paper by Scapin et al. ${ }^{36}$ the best yields for FF production from rice husks were obtained with $4 \mathrm{~h}$ of reaction at $120^{\circ} \mathrm{C}(34 \%)$ and for soy peel with $3 \mathrm{~h}$ of reaction at $120^{\circ} \mathrm{C}(59 \%)$. In this same work, HMF was produced with yields of 8.7 and $3.4 \%$ for rice and soy husks, respectively.

Wang et al.$^{49}$ analyzed the influence of $\mathrm{HCl}$ dosage, temperature and reaction time $\left(130^{\circ} \mathrm{C}\right.$ for $\left.2 \mathrm{~h}\right)$ using cottonseed for the production of HMF with [BMIM][Cl]. When the amount of $\mathrm{HCl}$ added was $20 \%$ (relative to the cottonseed hull), the yield of HMF reached $51 \%$. However, when the amount of $\mathrm{HCl}$ was increased, its yield decreased to $33 \%$. FF yield had a similar trend but was significantly lower than HMF. In the present work we observed inverse behavior, FF was produced with yields that are higher than HMF, which can be explained by the differences in biomass composition (different hemicellulose and cellulose content) and the type of acid used (the nature of the acid used influences the hydrolysis efficiency).

High glucose conversion rates were found ( $>90 \%$ ), but the obtained LA yield was $23.7 \%$. A part of the converted glucose probably formed other products such as formic acid, acetic acid, 5-HMF, and other unidentified compounds. ${ }^{50}$ According to the literature, Kang and $\mathrm{Yu}^{50}$ found yields of
$12-16 \%$ for eucalyptus wood, while Bevilaqua et al. ${ }^{37}$ and Kumar et al. ${ }^{51}$ for rice husks, found yields in the range of $10-59$ and $2-38 \%$, respectively. It is noteworthy that the sample in question of this study presents a high composition of essential oils (found in extractives), which decreases the theoretical yield of LA when it is compared to rice husks and eucalyptus sawdust, for example.

\section{Design and surface of response}

The analysis of variance (ANOVA) applied to obtain the mathematical model with significance level $\alpha=0.05$, verified the significance of the second order model established for HMF and FF, obtaining values of $F=0.00167$ and 0.004494 , respectively (Table 3 ).

The ANOVA applied also demonstrated that for HMF production the temperature $\left(\mathrm{x}_{2}{ }^{2}\right)$ and the interaction between time and temperature $\left(\mathrm{x}_{1} \mathrm{x}_{2}\right)$ are significant and for furfural production only the temperature $\left(\mathrm{x}_{2}\right.$ and $\left.\mathrm{x}_{2}^{2}\right)$ is significant. This can be concluded by analyzing the Pareto diagram for the HMF (Figure 3a) and FF (Figure 3b) yield data after the pequi bark reaction, from which it was observed that in this experiment the temperature variable is significant, having a strong influence on HMF as well as FF yields, since it 
Table 3. Analysis of variance for HMF and FF yield from pequi bark

\begin{tabular}{|c|c|c|c|c|c|c|c|c|c|c|}
\hline \multirow{2}{*}{$\begin{array}{l}\text { Variation } \\
\text { source }\end{array}$} & \multicolumn{2}{|c|}{ Sum of squares } & \multicolumn{2}{|c|}{ Degrees of freedom } & \multicolumn{2}{|c|}{ Mean square } & \multicolumn{2}{|c|}{$F_{\text {Value }}$} & \multicolumn{2}{|c|}{$F_{\text {Table }}$} \\
\hline & HMF & FF & HMF & $\mathrm{FF}$ & HMF & $\mathrm{FF}$ & HMF & $\mathrm{FF}$ & $\mathrm{HMF}$ & $\mathrm{FF}$ \\
\hline Regression & 36241.0 & 1083250.5 & 5 & 5 & 7248.2 & 216650.1 & 23.9 & 5.3 & $F_{0.05}=0.00167$ & $F_{0.05}=0.004494$ \\
\hline Residuals & 1513.4 & 202963.8 & 5 & 5 & 302.7 & 40592.8 & & & & \\
\hline Total & 377540.3 & 1286214.3 & 10 & 10 & & & & & & \\
\hline
\end{tabular}

$F_{\text {Value }}$ : test $F$ value; $F_{\text {Table: }}$ tabulated $F$ value; HMF: 5-hydroxymethylfurfural; FF: furfural.

meets the criterion of having effects superior to $p_{\text {value }}$ (descriptive level), which indicates the confidence level used in the design. It does not happen with the reaction time variable, which for both products of interest of this work was less influent in the obtained result. Evaluating also the relationship between time and temperature, it is possible to observe that for HMF it was presented with little relevance, which was different for furfural, where the relationship was relevant for the obtained results. It is also verified that the model fit is satisfactory, since the determination coefficient $\left(\mathrm{R}^{2}\right)$ for HMF and FF was 0.9599 and 0.08422 , respectively.

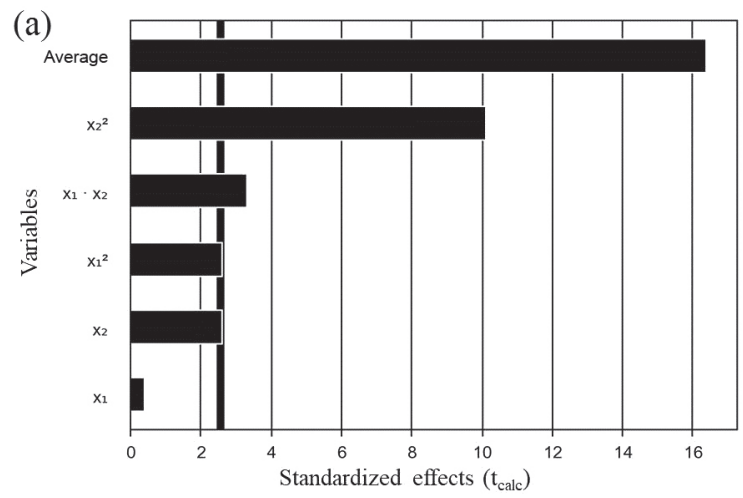

Figure 4 shows the response surfaces generated for HMF (Figure 4a) and furfural (Figure 4b) yields, where it can be observed that for the system studied, temperature and time conditions show a maximum yield of HMF in the central region of the chart, after $2 \mathrm{~h}$ of reaction at $120{ }^{\circ} \mathrm{C}$. As described in the literature, ${ }^{1,7,16}$ low temperatures do not favor HMF formation and high temperatures favor its degradation.

The model equation was obtained with the variables time $\left(\mathrm{x}_{1}\right)$ and temperature $\left(\mathrm{x}_{2}\right)$. The equations for the coded variables are described below, where $\mathrm{Y}_{1}$ represents the yield in $\mathrm{HMF}$ and $\mathrm{Y}_{2}$ the yield in FF.

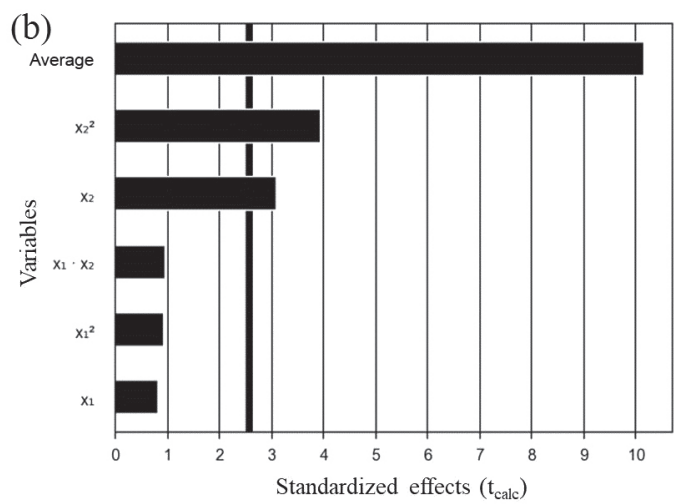

Figure 3. Pareto diagram of (a) HMF and (b) FF DCCR standard effects, where $x_{1}$ is time and $x_{2}$ is temperature.

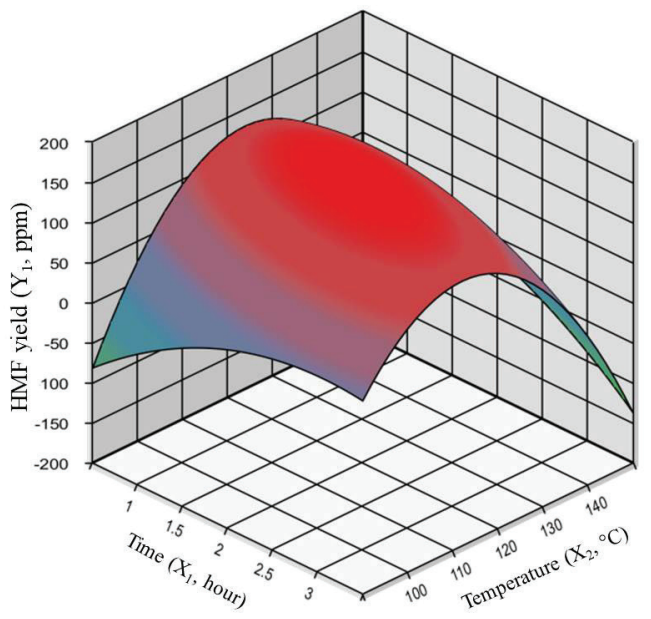

(A)

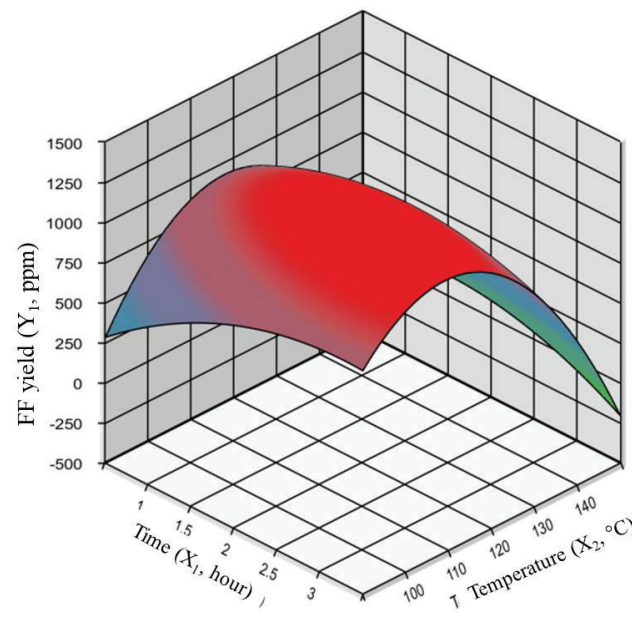

(B)

Figure 4. Response surface for (a) HMF and (b) FF. 
$\mathrm{Y}_{1}=164.70-2.55 \mathrm{x}_{1}-19.16 \mathrm{x}_{1}^{2}-15.90 \mathrm{x}_{2}-73.85 \mathrm{x}_{2}^{2}-$ $28.84 \mathrm{x}_{1} \mathrm{x}_{2}$

$\mathrm{Y}_{2}=1182.36+58.26 \mathrm{x}_{1}-79.27 \mathrm{x}_{1}^{2}-221.05 \mathrm{x}_{2}-$ $332.95 \mathrm{x}_{2}^{2}-96.19 \mathrm{x}_{1} \mathrm{x}_{2}$

\section{Conclusions}

The use of residual biomass in biorefinery processes is extremely important for a society that seeks to add value to products that are economically and environmentally sound. In view of this, the reuse of pequi bark eliminates an environmental liability, helps to reduce the cost involved with the production of high value-added chemicals and it is a biomass widely distributed throughout the Brazilian cerrado. Chemical characterization has shown that pequi bark can serve as a precursor for high added value compounds. The production process of furanic compounds using DCCR, combined with the use of IL [BMIM][Br] was efficient for FF production $(65 \%)$, but resulted in low HMF (3\%). The yield of LA was $23.7 \%$ with a selectivity of $8.7 \%$.

\section{Acknowledgments}

The authors are grateful to Conselho Nacional de Desenvolvimento Científico (CNPq) for the scholarships, Universidade Federal do Tocantins (UFT) for the financial support and to Instituto Federal do Tocantins (IFTO) by the Support Program, PAP/INOVA (No. 30/2019).

\section{Author Contributions}

Elisandra Scapin and Magale K. D. Rambo were responsible for the conceptualization, data curation, formal analysis, project administration, visualization, writing original draft, review and editing; Guenther C. C. Viana for the conceptualization, data curation, visualization and writing original draft; Mariana S. Borges for the data formal analysis, software, and writing original draft; Michele C. D. Rambo for the formal analysis, software, funding acquisition and writing review and editing; Cláudio Carneiro for the data curation, software, validation, writing original draft, review and editing.

\section{References}

1. Yi, Y.; Lee, J.; Chung, C.; Environ. Chem. Lett. 2015, 13, 173.

2. Nguyen, C. V.; Lewis, D.; Chen, W.-H.; Huang, H.-W.; ALOthman, Z. A.; Yamauchi, Y.; Wu, K. C.-W.; Catal. Today 2016, 278, 344.
3. Yu, I. K. M.; Tsang, D. C. W.; Yip, A. C. K.; Chen S. S.; Ok, Y. S.; Poon, C. S.; Bioresour. Technol. 2017, 237, 222.

4. Teong, S. P.; Yi, G.; Zhang, Y.; Green Chem. 2014, 16, 2015.

5. Galaverna, R.; Pastre, J. C.; Rev. Virtual Quim. 2017, 9, 248.

6. Rout, P. K.; Nannaware, A. D.; Prakash, O.; Rajasekharan, L.; Chem. Eng. Sci. 2015, 142, 318.

7. Rosatella, A. A.; Simeonov, S. P.; Frade, R. F. M.; Afonso, C. A. M.; Green Chem. 2011, 13, 754.

8. Kuster, B. F. M.; Starch 1990, 42, 314.

9. de Carvalho, E. G. L.; Rodrigues, F. A.; Monteiro, R. S.; Ribas, R. M.; da Silva, M. J.; Biomass Convers. Biorefin. 2018, 8, 635.

10. Luo, Y.; Li, Z.; Li, X.; Liu, X.; Fan, J.; Clark, J. H.; Hu, C.; Catal. Today 2019, 319, 14

11. Di, X.; Zhang, Y.; Fu, J.; Yu, Q.; Wang, Z.; Yuan, Z.; Process Biochem. 2019, 81, 33.

12. Liang, C.; Hu, Y.; Wang, Y.; Wu, L.; Zhang, W.; Process Biochem. 2018, 73, 124.

13. Chen, S. S.; Maneerung, T.; Tasang, D. C. W.; Ok, Y. S.; Wang, C.-H.; Chem. Eng. J. 2017, 328, 246.

14. Serrano-Ruiz, J. C.; Dumesic, J. A.; Energy Environ. Sci. 2011, 4,83 .

15. Sanborn, A. J.; US pat. $7579489 B 22009$.

16. Putten, R.-J. V.; Waal, J. C. V. D.; de Jong, E.; Rasrendra, C. B.; Heeres, H. J.; de Vries, J. G.; Chem. Rev. 2013, 113, 1499.

17. Li, H.; Yang, S.; Int. J. Chem. Eng. 2014, 7, 978.

18. Kang, S.; Fu, J.; Zhang, G.; Renewable Sustainable Energy Rev. 2018, 94, 340.

19. Stark, A.; Energy Environ. Sci. 2011, 4, 19.

20. Olivier-Bourbigou, H.; Magna, L.; Morvan, D.; Appl. Catal., A 2010, 373, 1.

21. Zhang, L.; Xi, G.; Zhang, J.; Yu, H.; Wang, X.; Bioresour. Technol. 2017, 224, 656.

22. Tiong, Y. W.; Yap, C. L.; Gan, S.; Yap, W. S. P.; IOP Conf. Ser.: Earth Environ. Sci. 2018, 164, 012007.

23. Asim, A. M.; Uroos, M.; Naz, S.; Sultan, M.; Griffin, G.; Muhammad, N.; Khan, A. S.; J. Mol. Liq. 2019, 287, 110943.

24. Amorim, D. J.; Rezende, H. C.; Oliveira, É. L.; Almeida, I. L. S.; Coelho, N. M. M.; Matos, T. N.; Araújo, C. S. T.; J. Braz. Chem. Soc. 2016, 27, 616.

25. Cardoso, C. M. M.; Zavarize, D. G.; Vieira, G. E. G.; Ind. Crops Prod. 2019, 139, 111485.

26. Oliveira, M. E. B.; Guerra, N. B.; Barros, L. M.; Alves, R. E.; Aspectos Agronômicos e de Qualidade do Pequi; Embrapa Agroindústria Tropical: Fortaleza, 2008.

27. Ribeiro, M. C.; Boas, E. V. B. V.; Riul, T. R.; Pantoja, L.; Marinho, H. A.; Santos, A. S.; Cienc. Tecnol. Aliment. 2012, $32,386$.

28. Bezerra, N. K. M. S.; Barros, T. L.; Coelho, N. P. M. F.; Rev. Bras. Plant. Med. 2015, 17, 875.

29. Rambo, M. K. D.; Alexandre, G. P.; Rambo, M. C. D.; Alves, A. R.; Garcia, W. T.; Baruque, E.; Food Sci. Technol. 2015, 35, 605. 
30. Sluiter, A.; Hames, B.; Ruiz, R.; Scarlata, C.; Sluiter, J.; Templeton, D.; Crocker, D.; NREL/TP-510-42618: Determination of Structural Carbohydrates and Lignin in Biomass; National Renewable Energy Laboratory (NREL): Golden, USA, 2008.

31. ASTM D3173-87: Standard Method for Determination of Moisture Content in Biomass; American Society for Testing and Materials (ASTM), West Conshohocken, PA, 2003.

32. ASTM D3174-04: Standard Method for Ash in the Analysis Sample of Coal and Coke; American Society for Testing and Materials (ASTM), West Conshohocken, PA, 2004.

33. Trujillo, A. I.; Marichal, M. J.; Carriquiry, M.; Anim. Feed Sci. Technol. 2010, 161, 49.

34. Dharaskar, S. A.; Varma, M. N.; Shende, D. Z.; Yoo, C. Y.; Kailas, L.; Wasewar, K. L.; Arabian J. Chem. 2016, 9, 578.

35. Rodrigues, M. I.; Costa, P.; Protimiza Experimental Design Software; Protimiza, Campinas, Brazil, 2014.

36. Scapin, E.; Rambo, M. K. D.; Viana, G. C. C.; Marasca, N.; Lacerda, G. E.; Rambo, M. C. D.; Fernandes, R. M. N.; Food Sci. Technol. 2019, DOI: 10.1590/fst.04419.

37. Bevilaqua, D. B.; Rambo, M. K. D.; Rizzetti, T. M.; Cardoso, A. L.; Martins, A. F.; J. Cleaner Prod. 2013, 47, 96.

38. Tiong, Y. W.; Yap, C. L.; Gan, S.; Yap, W. S. P.; Ind. Crops Prod. 2019, 128, 221.

39. Cai, C.; Qiying, L.; Tan, J.; Wang, T.; Zhang, Q.; Longlong, M.; BioResources 2017, 12, 1201.
40. da Paz, J. G.; Pacheco, P.; da Silva, C. O.; Pascoal, G. B.; Rev. Cient. Linkania Master 2014, 1, 73.

41. Ramos, K. M. R.; de Souza, V. A. B.; Rev. Bras. Frutic. 2011, 33, 500 .

42. Dharaskar, S. A.; Varma, M. N.; Shende, D. Z.; Yoo, C. K.; Wasewar, K. L.; Sci. World J. 2013, DOI 10.1155/2013/395274.

43. Rajkumar, T.; Rao, G. R.; J. Chem. Sci. 2008, 120, 587.

44. Tao, F.; Song, H.; Chou, L.; Carbohydr. Res. 2011, 346, 58.

45. Yu, I. K. M.; Tsang, D. C. W.; Bioresour. Technol. 2017, 238, 716.

46. Yang, Y.; Hu, C. W.; Abu-Omar, M. M.; Green Chem. 2012, 14, 509.

47. Wang, P.; Yu, H.; Zhan, S.; Wang, S.; Bioresour. Technol. 2011, 102, 4179.

48. Rambo, M. K. D.; Rambo, M. C. D.; Melo, P. M.; de Oliveira, N. M. L.; Nemet, Y. K. S.; Scapin, E.; Viana, G. C. C.; Bertuol, D. A.; J. Braz. Chem. Soc. 2020, 31, 273.

49. Wang, S.; Du, Y.; Zhang, P.; Cheng, X.; Qu, Y.; Korean J. Chem. Eng. 2014, 31, 2286.

50. Kang, S.; Yu, J.; Biomass Bioenergy 2016, 95, 214.

51. Kumar, S.; Ahluwalia, V.; Kundu, P.; Sangwan, R. S.; Kansal, S. K.; Runge, T. M.; Elumalai, S.; Bioresour. Technol. 2018, 251,143 .

Submitted: October 15, 2019 Published online: February 6, 2020 